\title{
Research Article \\ Effect of Carbon Supported Pt Catalysts on Selective Hydrogenation of Cinnamaldehyde
}

\author{
Qing Han, Yunfei Liu, Dong Wang, Fulong Yuan, Xiaoyu Niu, and Yujun Zhu \\ Key Laboratory of Functional Inorganic Material Chemistry, School of Chemistry and Materials, Heilongjiang University, \\ Ministry of Education, Harbin 150080, China
}

Correspondence should be addressed to Xiaoyu Niu; niuxiaoyu2000@126.com and Yujun Zhu; yujunzhu@hlju.edu.cn

Received 4 May 2016; Accepted 28 July 2016

Academic Editor: Ioannis D. Kostas

Copyright (C) 2016 Qing Han et al. This is an open access article distributed under the Creative Commons Attribution License, which permits unrestricted use, distribution, and reproduction in any medium, provided the original work is properly cited.

Selective hydrogenation of cinnamaldehyde (CAL) to cinnamyl alcohol (COL) is of both fundamental and industrial interest. It is of great significance to evaluate the possible differences between different supports arising from metal dispersion and electronic effects, in terms of activity and selectivity. Herein, Pt catalysts on different carbon supports including carbon nanotubes (CNTs) and reduced graphene oxides (RGO) were developed by a simple wet impregnation method. The resultant catalysts were well characterized by XRD, Raman, $\mathrm{N}_{2}$ physisorption, TEM, and XPS analysis. Applied in the hydrogenation of cinnamaldehyde, $3.5 \mathrm{wt} \% \mathrm{Pt} / \mathrm{CNT}$ shows much higher selectivity towards cinnamyl alcohol (62\%) than $3.5 \mathrm{wt} \% \mathrm{Pt} / \mathrm{RGO} @ \mathrm{SiO}_{2}$ (48\%). The enhanced activity can be ascribed to the high graphitization degree of CNTs and high density of dispersed Pt electron cloud.

\section{Introduction}

With the rapid development of catalytic science, controlling the reaction selectivity is particularly significant $[1,2]$. As a typical example, selective hydrogenation of $\alpha, \beta$-unsaturated aldehydes is of both fundamental and industrial importance [3-5]. For instance, the hydrogenation of cinnamaldehyde (CAL) can produce cinnamyl alcohol (COL), hydrocinnamaldehyde (HALD), and hydrocinnamyl alcohol (HALC) (Scheme 1) [6-8]. COL is generally considered to be the most challenging product to obtain and is a type of important organic intermediates for chemical synthesis, which has been widely used in perfume, cosmetics, medicines, and fungicides industries $[3,4]$. However, the selective production of COL is difficult because the hydrogenation of the $\mathrm{C}=\mathrm{C}$ bond is thermodynamically favored over that of the $\mathrm{C}=\mathrm{O}$ group. Therefore, the development of catalysts for this class of reactions is still challenging and highly desired.

Recently, a large number of homogeneous catalysts such as metal hydrides, aluminium isopropoxide, and others have been developed for selective hydrogenation of cinnamaldehyde to cinnamic alcohol $[9,10]$; however, efficient separation and recovery of these advanced catalysts from reaction vessel are still a challenge, which prevents their widespread applications [11]. To this end, the development of heterogeneous catalysts on various supports provides a promising solution because of its environment-friendly property, ability to selectively hydrogenate, and simple method to recover $[5,9]$. A number of noble metal (e.g., Pt, Pd, Ir, and Ru) and nonnoble metal (e.g., $\mathrm{Fe}, \mathrm{Co}, \mathrm{Ni}$, and $\mathrm{Cu}$ ) nanoparticles have been demonstrated as effective phase for this catalytic reaction [1221]. A great deal of parameters, such as the nature of the active metal, its surface structures, particle sizes, contents, the methods of catalyst preparation, and the reaction conditions could influence the activity and selectivity $[3,6,22-24]$. Among them, the support, which maximizes the active surface area of metal catalysts by dispersing them over its surface, plays a key role in both the activity and the selectivity in the targeted selective hydrogenation due to the interaction between the support and nanoparticles [25]. For example, various reducible oxides such as $\mathrm{CeO}_{2}$ [26], $\mathrm{MnO}_{2}$ [27], $\mathrm{SnO}_{2}$ [28], $\mathrm{TiO}_{2}[29,30]$, and $\mathrm{ZnO}$ [31] have been used as the supports and were found to be able to improve the selectivity toward COL production because of strong metal-support interactions, which can influence the degree of reduction, metal dispersion, and evolution of the active phase. 


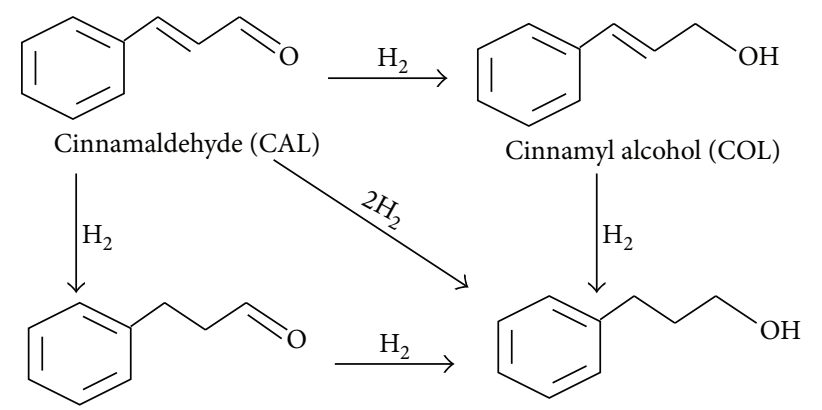

Hydrocinnamaldehyde (HALD)

Hydrocinnamyl alcohol (HALC)

SCHEME 1: Reaction pathways for cinnamaldehyde hydrogenation.

In addition to metal oxides, owning to the unique structures and properties, various carbon materials such as carbon nanofibers, carbon nanotubes (CNT), and reduced graphene oxides (RGO) have also been studied as effective supports for metal nanoparticles toward hydrogenation of unsaturated aldehyde [32-36]. We have found that graphene-supported $\mathrm{Pt}$ catalysts exhibit excellent catalytic performances in terms of selectivity for the hydrogenation of unsaturated aldehydes [37]. Unfortunately, the key factor of different carbon supports controlling the activity and selectivity still remains unclear.

Indeed, CNTs, which are the one-dimensional (1D) tubular structure of graphite, are totally different from graphene (2D planar structure). Therefore, it would be interesting to evaluate the possible differences between different carbon materials arising from metal dispersion and electronic effects, in terms of activity and selectivity. Herein, we have attempted to address this issue through investigating Pt catalysts on different carbon supports including CNTs and RGO, which were evaluated for the selective hydrogenation of CAL. $3.5 \mathrm{wt} \% \mathrm{Pt}$ nanoparticles deposited on CNTs and RGO were prepared by the same wet impregnation method and were denoted as $3.5 \mathrm{wt} \% \mathrm{Pt} / \mathrm{CNT}$ and $3.5 \mathrm{wt} \% \mathrm{Pt} / \mathrm{RGO} @ \mathrm{SiO}_{2}$, respectively. It was found that the selectivity of COL is different for the Pt supported on different carbon. $3.5 \mathrm{wt} \% \mathrm{Pt} / \mathrm{CNT}$ shows much higher selectivity towards cinnamyl alcohol (62\%) than 3.5 wt\% Pt/RGO@SiO 2 (48\%). The effects of CNTs and RGO on the properties of catalysts were investigated, indicating the graphitization degree of support plays an important role in the sorption of CAL and Pt species.

\section{Material and Methods}

\subsection{Synthesis of RGO@SiO 2 Supports}

(3-Aminopropyl) Triethoxysilane (APTES) Modified Silica $\mathrm{Gel}$ (Aladdin $200 \mathrm{~m}^{2} / \mathrm{g}$ ). In a typical process, after vacuum drying at $110^{\circ} \mathrm{C}$ for $24 \mathrm{~h}, 5.0 \mathrm{~g}$ silica gel was added into APTES/toluene solution. The mole ratio of APTES to silica gel was maintained at $1: 2$. The mixed solution was stirred at $100^{\circ} \mathrm{C}$ for $24 \mathrm{~h}$. After cooling to room temperature, the product was washed by using toluene 4 times $(100 \mathrm{~mL} /$ times $)$ and chloroform 4 times (100 mL/time), respectively. Next, the product was soaked in methanol/water solution $(1: 10, \mathrm{v} / \mathrm{v})$ for $2 \mathrm{~h}$ and it was repeated 4 times to remove the organic residues in the process of modification. The resultant product was dried at $100^{\circ} \mathrm{C}$ for $24 \mathrm{~h}$, marked as APTES-SiO 2 .

RGO@SiO 2 Supports. In a typical process, APTES-SiO ${ }_{2}$ was added into graphene oxide solution. The quality ratio of graphene oxide to APTES-SiO 2 was kept at 1:9. The $\mathrm{pH}$ value of the mixture solution was adjusted to 4.0 by $\mathrm{NaOH}$ $(0.1 \mathrm{~mol} / \mathrm{L})$ solution. After stirring for $1 \mathrm{~h}, \mathrm{FeCl}_{2}$ solution was slowly added to the reaction vessel. Subsequently, $\mathrm{NaBH}_{4}$ solution $(1 \mathrm{~mol} / \mathrm{L})$ was added to the mixture and stirred for $10 \mathrm{~min}$. Next, $\mathrm{HCl}$ aqueous solution was added to remove the excess iron powders. The resultant sample was thoroughly washed by water to remove chloride ions, which was checked by $\mathrm{AgNO}_{3}$ solution $(1 \mathrm{~mol} / \mathrm{L})$. Then, the product was washed by ethanol and dried at $80^{\circ} \mathrm{C}$ for $10 \mathrm{~h}$ under vacuum drying, which is denoted as RGO@SiO 2 .

2.2. Preparation of $3.5 w t \%$ Pt/RGO@SiO 2 and $3.5 w t \%$ Pt/CNTs. $3.5 \mathrm{wt} \% \mathrm{Pt} / \mathrm{RGO} @ \mathrm{SiO}_{2}$ was prepared in a typical process and the $\mathrm{RGO} @ \mathrm{SiO}_{2}$ supports ( $0.5 \mathrm{~g}$ ) were first suspended in deionized water $(50 \mathrm{~mL})$ and ultrasonicated for $0.5 \mathrm{~h}$. Then, $\mathrm{H}_{2} \mathrm{PtCl}_{6}(19.3 \mathrm{mmol} / \mathrm{L})$ solution was added to the slurry. Next, the mixture solution was put into ice bath and stirred vigorously for $0.5 \mathrm{~h}$. The temperature of ice bath was kept at $2-4^{\circ} \mathrm{C}$ and the $\mathrm{pH}$ value of the mixture solution was adjusted to 8.0 by $\mathrm{NaOH}(0.1 \mathrm{~mol} / \mathrm{L})$ solution. Afterwards, an excess of $\mathrm{NaBH}_{4}(0.4 \mathrm{~mol} / \mathrm{L})$ solution was added to the mixture under vigorous stirring. After $3 \mathrm{~h}$, the mixture was statically placed in the ice bath for $10 \mathrm{~h}$. Finally, the product (3.5 wt\% Pt/RGO@SiO 2 catalysts) was obtained after filtrating, washing with deionized water until no chloride was detected, washing with ethanol, and drying at $60^{\circ} \mathrm{C}$ for $10 \mathrm{~h}$. The $3.5 \mathrm{wt} \% \mathrm{Pt} / \mathrm{CNTs}$ catalyst was prepared by following the same method.

2.3. Catalyst Characterization. X-ray diffraction (XRD) patterns were obtained with a Rigaku D/max-IIIB diffractometer by using $\mathrm{Cu}-\mathrm{K}_{\alpha}(\lambda=1.5406 \AA)$ radiation. The accelerating voltage and the applied current were $40 \mathrm{kV}$ and $20 \mathrm{~mA}$, respectively. Raman spectra were recorded with a Jobin Yvon HR 800 micro-Raman spectrometer at $457.9 \mathrm{~nm}$. The laser beam was focused on the sample with a $50 \mathrm{x}$ objective. Transmission electron microscopy (TEM) experiments were carried out with a JOEL model JEM-2100 electron microscope working at an acceleration voltage of $200 \mathrm{kV}$. The samples for the TEM measurements were suspended in ethanol and supported onto a holey carbon film on a $\mathrm{Cu}$ grid. X-ray photoemission spectroscopy (XPS) studies were carried out on a Kratos-AXIS ULTRA DLD with an $\mathrm{Al}-\mathrm{K}_{\alpha}$ radiation source. Nitrogen adsorption and desorption isotherms were measured at $77 \mathrm{~K}$ with a Micromeritics Tristar II 3020 analyzer. The sample was degassed under vacuum at $423 \mathrm{~K}$ for $4 \mathrm{~h}$ prior to measurements. The Brunauer-EmmettTeller (BET) method was utilized to calculate the specific surface areas using adsorption data in a relative pressure range from 0.05 to 0.25 . 
2.4. Catalytic Performance Measurements. The catalytic performances of $3.5 \mathrm{wt} \% \mathrm{Pt} / \mathrm{RGO} @ \mathrm{SiO}_{2}$ and $3.5 \mathrm{wt} \% \mathrm{Pt} / \mathrm{CNT}$ toward the hydrogenation of cinnamaldehyde were carried out in a $100 \mathrm{~mL}$ stirred autoclave. In briefly, catalyst $(50 \mathrm{mg})$ was immersed into $15 \mathrm{~mL}$ of isopropanol. The trace of dissolved oxygen was removed by flushing with nitrogen at 5 bar for 3 times and subsequently with hydrogen at 5 bar for 3 times. Then, the temperature was raised to $110^{\circ} \mathrm{C}$ under 10 bar of hydrogen for $1 \mathrm{~h}$, to reactivate the catalysts. Then, a mixture of cinnamaldehyde $(1.0 \mathrm{~g})$ and isopropanol $(15 \mathrm{~mL})$ was added into the autoclave. After flushing with nitrogen at 5 bar for 3 times and subsequently with hydrogen at 5 bar for 3 times, the reaction was allowed to proceed at $60^{\circ} \mathrm{C}$ under 10 bar of hydrogen. The products were analyzed on a gas chromatography (Agilent 7820A) equipped with an FID detector and an HP-5 capillary column $(30 \mathrm{~m} \times 0.32 \mathrm{~mm} \times$ $0.25 \mu \mathrm{m})$. The products were further identified by GC-MS (Agilent 6890/5973N).

\section{Results and Discussion}

Due to the poor dispersion of RGO support, RGO was dispersed on $\mathrm{SiO}_{2}$ to obtain the $\mathrm{RGO} @ \mathrm{SiO}_{2}$ support. Thus, 3.5 wt\% Pt/RGO@SiO 2 and 3.5 wt\% Pt/CNTs were prepared by reduction of $\mathrm{H}_{2} \mathrm{PtCl}_{6}$ using $\mathrm{NaBH}_{4}$ and used to research the effect of different carbon supported $\mathrm{Pt}$ catalysts on selective hydrogenation of cinnamaldehyde.

3.1. XRD Analysis. A sharp and strong diffraction peak at $27^{\circ}$ in $3.5 \mathrm{wt} \% \mathrm{Pt} / \mathrm{CNTs}$ was assigned to (002) facet of graphite, suggesting the ordered structure and high graphite degree of CNTs support (Figure 1). A weak and broad peak at $22.1^{\circ}$ in $3.5 \mathrm{wt} \% \mathrm{Pt} / \mathrm{RGO} @ \mathrm{SiO}_{2}$ can be assigned to the characteristic structure of RGO due to restacking effects, indicating the graphene oxide has been reduced to a certain degree. The results illustrate that the CNTs support has a higher graphitization degree than $\mathrm{RGO@SiO} 2$ support. Additional diffraction peaks were observed in the patterns of both catalysts at $39.7,46.4$, and $67.5^{\circ}$, which correspond to the (111), (200), and (220) crystalline planes of the facecentered cubic (fcc) Pt, respectively [38]. The average particle sizes of Pt nanoparticles are about 4.0 and $4.4 \mathrm{~nm}$ for $3.5 \mathrm{wt} \%$ $\mathrm{Pt} / \mathrm{RGO} @ \mathrm{SiO}_{2}$ and $3.5 \mathrm{wt} \%$ of Pt/CNTs, respectively, which are calculated by using the full width at half maximum of $\mathrm{Pt}$ (111) reflection based on Scherrer's equation [39].

3.2. Raman Spectroscopy. Raman is one of the useful tools for providing detailed structures of carbon materials, such as disorder and defect structure. Figure 2 shows the Raman spectra of 3.5 wt\% Pt/RGO@SiO 2 and 3.5 wt\% Pt/CNTs. In the Raman spectroscopy of both catalysts, the appearance of two prominent peaks, D $\left(1368 \mathrm{~cm}^{-1}\right)$ and $\mathrm{G}\left(1590 \mathrm{~cm}^{-1}\right)$ bands, is usually assigned to the breathing mode of $\kappa$-point phonons of $\mathrm{A}_{1 \mathrm{~g}}$ symmetry and the $\mathrm{E}_{2 \mathrm{~g}}$ phonons of $\mathrm{sp}^{2}$ carbon atoms, respectively $[40,41]$. It is well known that the increase in the intensity ratio of $\mathrm{D} / \mathrm{G}\left(I_{\mathrm{D}} / I_{\mathrm{G}}\right)$ accounts for a low crystalline degree of graphite materials. The $I_{\mathrm{D}} / I_{\mathrm{G}}$ values of $3.5 \mathrm{wt} \% \mathrm{Pt} / \mathrm{RGO} @ \mathrm{SiO}_{2}$ and $3.5 \mathrm{wt} \% \mathrm{Pt} / \mathrm{CNT}$ are 1.2 and

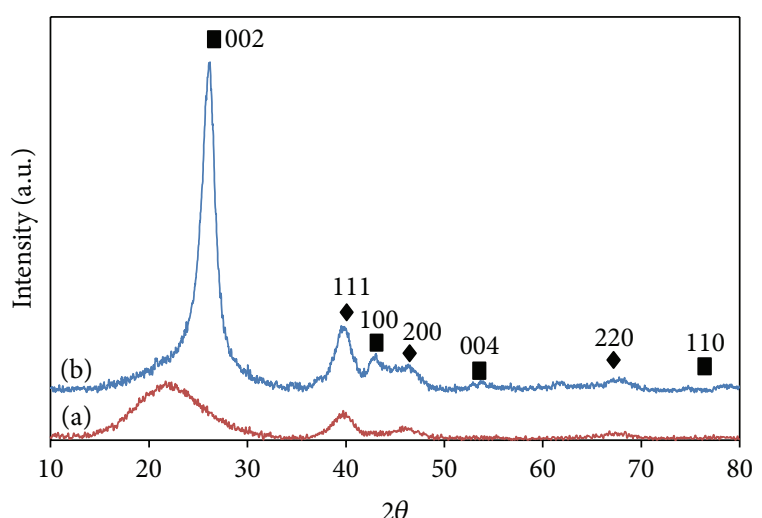

Graphite

- Pt

Figure 1: XRD patterns of (a) $3.5 \mathrm{wt} \% \mathrm{Pt} / \mathrm{RGO} @ \mathrm{SiO}_{2}$ and (b) $3.5 \mathrm{wt} \% \mathrm{Pt} / \mathrm{CNTs}$.

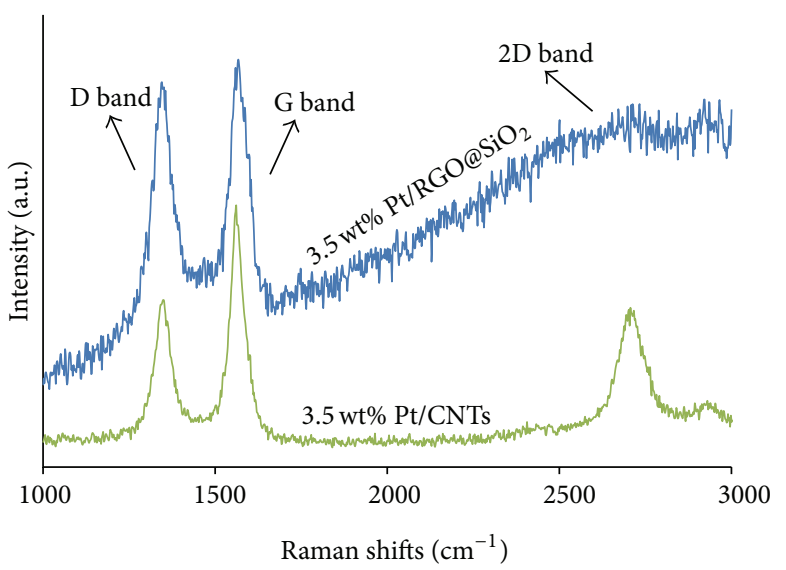

FIGURE 2: Raman spectra of $3.5 \mathrm{wt} \% \mathrm{Pt} / \mathrm{RGO} @ \mathrm{SiO}_{2}$ and $3.5 \mathrm{wt} \%$ $\mathrm{Pt} / \mathrm{CNTs}$.

0.82 , respectively (Table 1 ). It indicates that CNTs have a higher degree of graphitization than RGO support, which is in agreement with the XRD analysis. The $I_{2 \mathrm{D}} / I_{\mathrm{G}}$ ratio of $3.5 \mathrm{wt} \% \mathrm{Pt} / \mathrm{CNTs}$ is 0.70 , suggesting that the tube wall of CNTs support is thin. In contrast, the intensity of $2 \mathrm{D}$ peak of $3.5 \mathrm{wt} \% \mathrm{Pt} / \mathrm{RGO} @ \mathrm{SiO}_{2}$ catalyst is relatively weak, which is possibly caused by the reunion of RGO.

3.3. TEM Analysis. The morphology of $3.5 \mathrm{wt} \% \mathrm{Pt} /$ RGO@SiO 2 and 3.5 wt\% Pt/CNTs was investigated by TEM measurements, as shown in Figure 3. The structure of different carbon supports can be clearly distinguished. TEM images of $3.5 \mathrm{wt} \% \mathrm{Pt} / \mathrm{RGO} @ \mathrm{SiO}_{2}$ and $3.5 \mathrm{wt} \% \mathrm{Pt} / \mathrm{CNTs}$ catalysts show that a number of $\mathrm{Pt}$ nanoparticles were well dispersed on $1 \mathrm{D}$ intertwined CNTs and 2D planar RGO support, respectively (Figures 3(a) and 3(c)). Figures 3(e) and 3(f) show the particle size distribution of $\mathrm{Pt}$ nanoparticles, respectively. The mean particle size of $\mathrm{Pt}$ nanoparticles for the $3.5 w t \% \mathrm{Pt} / \mathrm{CNTs}$ and $3.5 \mathrm{wt} \% \mathrm{Pt} / \mathrm{RGO@SiO} 2$ is around $3.8 \mathrm{~nm}$ and $3.1 \mathrm{~nm}$, respectively. The results match 
TABLE 1: Physicochemical properties of $3.5 \mathrm{wt} \% \mathrm{Pt} / \mathrm{CNTs}$ and $3.5 \mathrm{wt} \% \mathrm{Pt} / \mathrm{RGO} @ \mathrm{SiO}_{2}$.

\begin{tabular}{|c|c|c|c|c|c|c|c|c|c|}
\hline \multirow{2}{*}{ Catalysts } & \multirow{2}{*}{$S_{\mathrm{BET}}{ }^{\mathrm{a}}\left(\mathrm{m}^{2} / \mathrm{g}\right)$} & \multirow{2}{*}{ Pt size $(\mathrm{nm})^{\mathrm{b}}$} & \multirow{2}{*}{$I_{\mathrm{D}} / I_{\mathrm{G}}{ }^{\mathrm{c}}$} & \multicolumn{3}{|c|}{ Cls content $(\%)$} & \multicolumn{3}{|c|}{ Pt species content $(\%) / \mathrm{BE}(\mathrm{eV})^{\mathrm{d}}$} \\
\hline & & & & $\mathrm{C}-\mathrm{C}$ & $\mathrm{C}=\mathrm{O}$ & $-\mathrm{COO}$ & $\mathrm{Pt}^{0} / \mathrm{BE}$ & $\mathrm{Pt}^{\mathrm{II}} / \mathrm{BE}$ & $\mathrm{Pt}^{\mathrm{IV}} / \mathrm{BE}$ \\
\hline $3.5 \mathrm{wt} \% \mathrm{Pt} / \mathrm{CNTs}$ & 147 & 4.0 & 0.82 & 64.2 & 28.1 & 7.7 & $58.6 / 71.6$ & $25.9 / 72.8$ & $15.5 / 75.1$ \\
\hline 3.5 wt\% Pt/RGO@SiO 2 & 152 & 4.4 & 1.2 & 16.5 & 69.7 & 11.7 & $19.0 / 71.4$ & $65.6 / 72.4$ & $15.4 / 74.9$ \\
\hline
\end{tabular}

${ }^{a}$ Values calculated from catalysts corrected mass (i.e., without mass induced by metal loading).

${ }^{\mathrm{b}} \mathrm{Pt}$ particle sizes were calculated from XRD patterns based on Scherrer's equation, respectively.

${ }^{c}$ Calculated from the Raman results using the intensities of D and G peaks.

${ }^{\mathrm{d}}$ Caculated from the XPS results.

TABLE 2: The catalytic performances of various catalysts toward the hydrogenation of cinnamaldehyde.

\begin{tabular}{|c|c|c|c|c|c|}
\hline \multirow{2}{*}{ Catalysts } & \multirow{2}{*}{ Conversion (\%) } & \multicolumn{4}{|c|}{ Selectivity (\%) } \\
\hline & & HALD & HALC & $\mathrm{COL}$ & Others $^{\mathrm{a}}$ \\
\hline $3.5 \mathrm{wt} \% \mathrm{Pt} / \mathrm{CNTs}^{\mathrm{b}}$ & 39 & 23 & 9 & 62 & 6 \\
\hline 3.5 wt\% Pt/RGO@SiO ${ }^{b}$ & 38 & 35 & 11 & 48 & 6 \\
\hline 3.5 wt $\%$ Pt/graphene ${ }^{b}$ [37] & 73 & 8 & 6 & 82 & 4 \\
\hline
\end{tabular}

a includes 1-(3-propoxyprop-1-enyl)benzene, cinnamyl formate, cinnamic acid, benzyl, cinnamate, 4,4-diphenylcyclohexa-1,5-dienyl acetate, and other condensation products that could not be identified by GC-MS because of their large molecular weights.

${ }^{\mathrm{b}}$ Reaction conditions: 10 bar $\mathrm{H}_{2}, 60^{\circ} \mathrm{C}$, and $2 \mathrm{~h}$.

well with the XRD analysis. Figures 3(b) and 3(d) are the corresponding high-resolution TEM (HRTEM) images. HRTEM images of Pt nanoparticles in both $3.5 \mathrm{wt} \% \mathrm{Pt} / \mathrm{CNTs}$ and 3.5 wt\% Pt/RGO@SiO 2 catalysts display the well-defined lattice fringes.

The measured lattice spacing values from the insertion of HRTEM images are $0.233 \mathrm{~nm}$ and $0.253 \mathrm{~nm}$, which can be well assigned to the (111) planes of the face-centered cubic Pt. HRTEM image of CNTs displays the (002) graphite planes with interlayer spacing of $0.34 \mathrm{~nm}$ mostly parallel to the tube axis (Figure 3(e)). In addition, Figure 3(f) also shows the welldefined lattice fringes of RGO. The lattice spacing values were calculated to be $0.287 \mathrm{~nm}$, which is corresponding to the (002) planes of graphite.

3.4. X-Ray Photoelectron Spectroscopy. XPS was used to study the surface nature and structure of $3.5 \mathrm{wt} \% \mathrm{Pt} / \mathrm{CNTs}$ and 3.5 wt\% Pt/RGO@SiO 2 (Figure 4). The high-resolution $\mathrm{Cls}$ spectra of the $3.5 \mathrm{wt} \% \mathrm{Pt} / \mathrm{CNT}$ and $3.5 \mathrm{wt} \% \mathrm{Pt} / \mathrm{RGO@SiO}$ could be deconvolved into three peaks at 284.6, 287.3, and $290.2 \mathrm{eV}$, which were assigned to the $\mathrm{C}$ element in $\mathrm{C}-\mathrm{C}, \mathrm{C}=\mathrm{O}$, and -COO groups, respectively, as shown in Figures 4(a) and 4(c). The content of C-C bond in $3.5 \mathrm{wt} \%$ $\mathrm{Pt} / \mathrm{CNTs}$ reached $64.2 \%$, and the half peak width is $0.62 \mathrm{eV}$, indicating that the CNTs have better graphitization degree, which is in agreement with the Raman and XRD results. In contrast, $3.5 \mathrm{wt} \% \mathrm{Pt} / \mathrm{RGO} @ \mathrm{SiO}_{2}$ displays a weak sharp peak at $284.6 \mathrm{eV}$ that only accounted for $16.5 \%$ of total carbon. And the half peak width is $0.79 \mathrm{eV}$, much wider than that of $3.5 \mathrm{wt} \% \mathrm{Pt} / \mathrm{CNT}$ catalyst. These results suggest that the graphene oxide can be partly reduced into RGO. The more content of $\mathrm{C}=\mathrm{O}$ and - $\mathrm{COO}$ bonds in $3.5 \mathrm{wt} \%$ $\mathrm{Pt} / \mathrm{RGO} @ \mathrm{SiO}_{2}$ may be resulting from the $\mathrm{SiO}_{2}$ substrate, which decrease the reducibility of graphene oxide. The Pt4f XPS spectra of $3.5 w t \%$ Pt/CNTs and $3.5 w t \%$ Pt/RGO@SiO are shown in Figures 4(b) and 4(d), respectively, together with their deconvolution into three spin-split states [42-44], as summarized in Table 1.

In terms of quantitation of the composition of the $\mathrm{Pt}$ nanoparticles, the contents of the surface $\mathrm{Pt}^{0}, \mathrm{Pt}^{\mathrm{II}}$, and $\mathrm{Pt}^{\mathrm{IV}}$ species in 3.5 wt\% Pt/CNTs and $3.5 w t \%$ Pt/RGO@SiO ${ }_{2}$ catalysts were estimated to be $58.6 / 25.9 / 15.5 \%$ and $19.0 / 65.6 /$ $15.4 \%$, respectively. Interestingly, the amount of $\mathrm{Pt}^{0}$ in $3.5 \mathrm{wt} \%$ $\mathrm{Pt} / \mathrm{CNTs}$ catalyst (58.6\%) is much higher than that of $3.5 \mathrm{wt} \%$ Pt/RGO@SiO 2 (19.1\%).

3.5. Catalytic Performances. The effect of different carbon supports for Pt nanoparticles on the selective hydrogenation of CAL was investigated and the results were summarized in Table 2. When the reaction time is $2 \mathrm{~h}$, the conversion of CAL is $39 \%$ over $3.5 \mathrm{wt} \% \mathrm{Pt} / \mathrm{CNTs}$, which is comparable to that of 3.5 wt $\%$ Pt/RGO@SiO 2 (38\%). The selectivity to COL for $3.5 \mathrm{wt} \% \mathrm{Pt} / \mathrm{CNTs}$ is $62 \%$, which is much better than that of 3.5 wt $\%$ Pt/RGO@SiO 2 (48\%). The selectivity to HALD and HALC is $35 \%$ and $11 \%$ over 3.5 wt $\%$ Pt/RGO@SiO 2 , respectively, which is corresponding to $23 \%$ and $9 \%$ for $3.5 \mathrm{wt} \%$ $\mathrm{Pt} / \mathrm{CNTs}$. It indicates that $3.5 \mathrm{wt} \% \mathrm{Pt} / \mathrm{CNT}$ is more favor of the hydrogenation of $\mathrm{C}=\mathrm{O}$ bond of cinnamaldehyde. In both cases, a minor quantity of acetal by-product was detected.

The recycling experiments were carried out over $3.5 \mathrm{wt} \%$ Pt/CNTs and 3.5 wt\% Pt/RGO@SiO 2 catalysts and shown in Figures 5 and 6, respectively. The catalysts were reused directly without any treatment after being precipitated and separated from the reaction solution. After four cycles, the activity of $3.5 \mathrm{wt} \% \mathrm{Pt} / \mathrm{CNTs}$ was a slight decrease, the conversion of CAL declined only from $39 \%$ to $32 \%$, and the selectivity to COL decreased from $62 \%$ to $53 \%$ (Figure 5 ). And, for $3.5 \mathrm{wt} \% \mathrm{Pt} / \mathrm{RGO} @ \mathrm{SiO}_{2}$ catalyst, the conversion to CAL and selectivity to COL after four catalytic cycles decreased to $26 \%$ and $34 \%$, respectively (Figure 6). In general, the catalytic stability of $3.5 \mathrm{wt} \% \mathrm{Pt} / \mathrm{CNTs}$ is higher than that of $3.5 \mathrm{wt} \% \mathrm{Pt} / \mathrm{RGO} @ \mathrm{SiO}_{2}$ catalyst. 


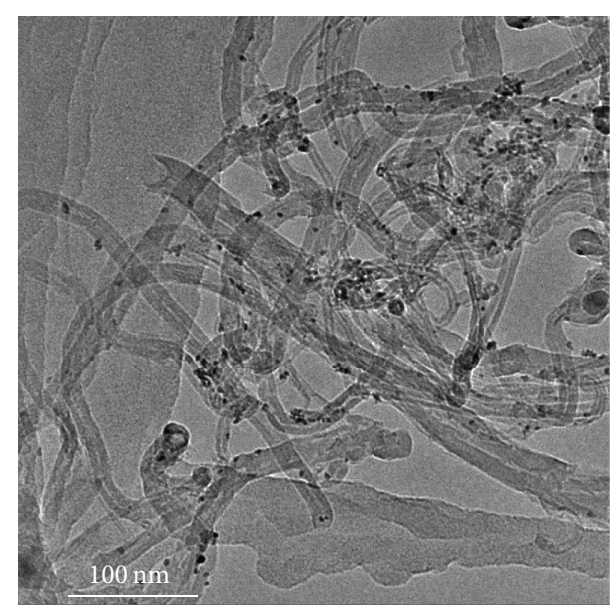

(a)

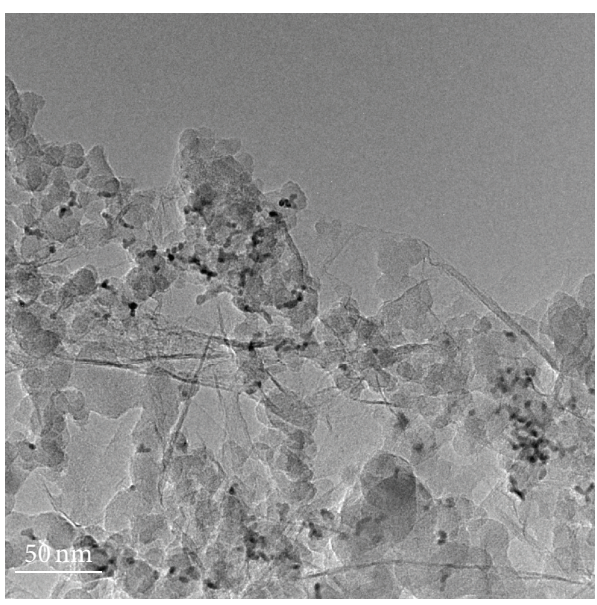

(c)

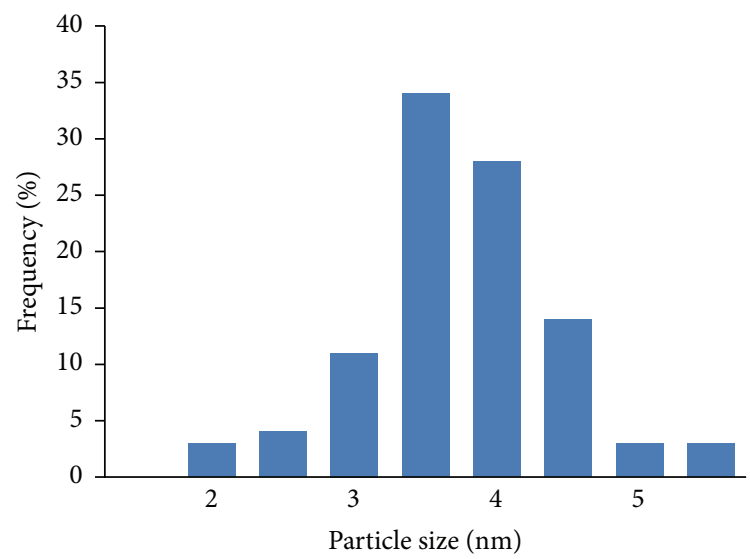

(e)

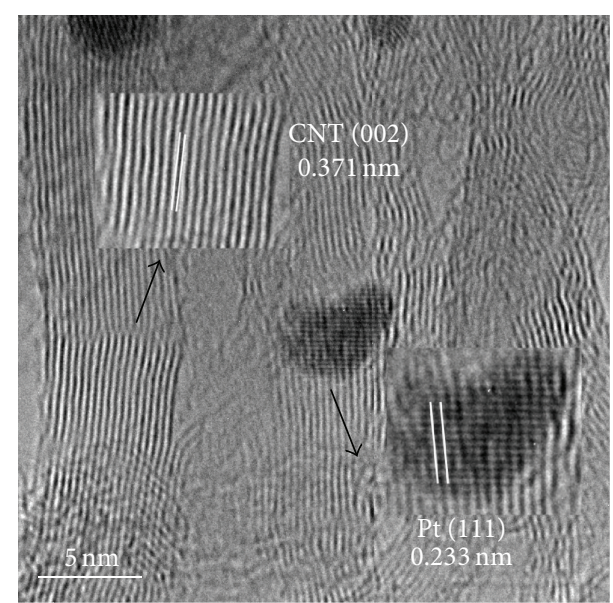

(b)

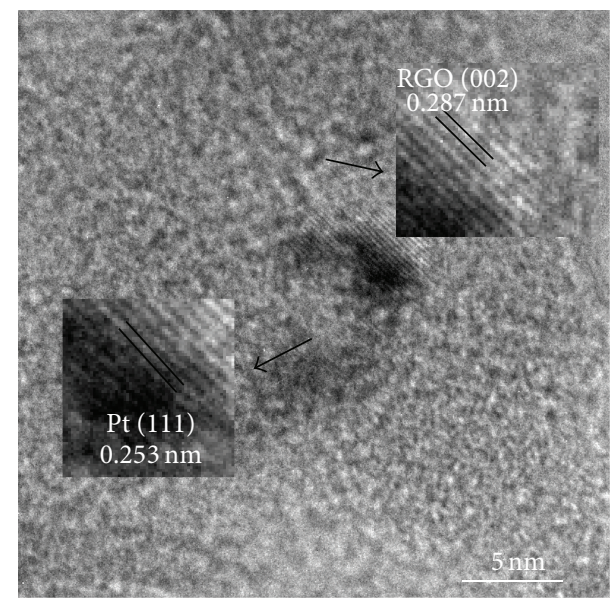

(d)

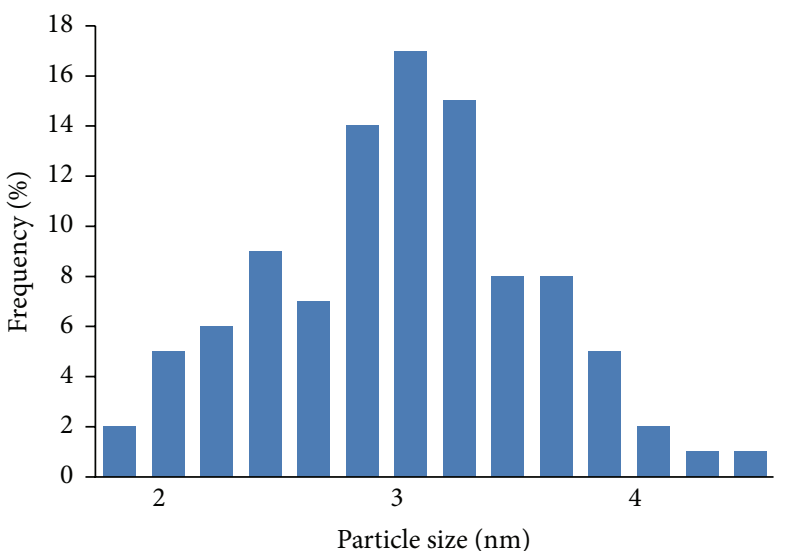

(f)

Figure 3: TEM images of (a, b) $3.5 \mathrm{wt} \% \mathrm{Pt} / \mathrm{CNTs}$ and (c, d) $3.5 \mathrm{wt} \% \mathrm{Pt} / \mathrm{RGO@SiO}$ catalysts; Pt particle size distributions of (e) $3.5 \mathrm{wt} \%$ $\mathrm{Pt} / \mathrm{CNTs}$ and (f) $3.5 \mathrm{wt} \% \mathrm{Pt} / \mathrm{RGO} @ \mathrm{SiO}_{2}$; the insets in panel (b and d) are the corresponding HRTEM images of CNT, Pt nanoparticle, and reduced graphene oxides (RGO).

The difference in selectivity for $3.5 \mathrm{wt} \% \mathrm{Pt} / \mathrm{CNTs}$ and $3.5 \mathrm{wt} \%$ Pt/RGO@SiO 2 with same conversion may be attributed to the Pt species and supports. According to above characterization results, similar mean particle size values were obtained for $3.5 \mathrm{wt} \% \mathrm{Pt} / \mathrm{CNTs}$ and $3.5 \mathrm{wt} \%$ $\mathrm{Pt} / \mathrm{RGO} @ \mathrm{SiO}_{2}$ synthesized here, but high selectivity was seen only with the $3.5 \mathrm{wt} \% \mathrm{Pt} / \mathrm{CNTs}$ sample. It is seen that other factors may account for the good selectivity to COL with 


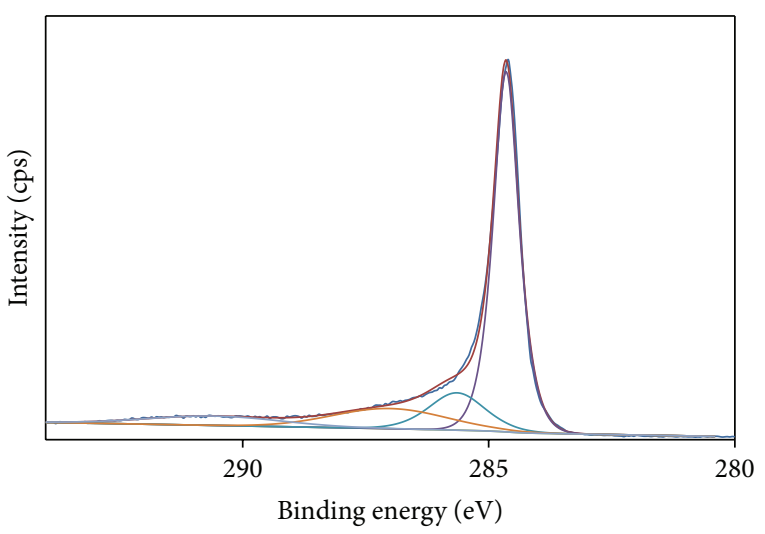

(a)

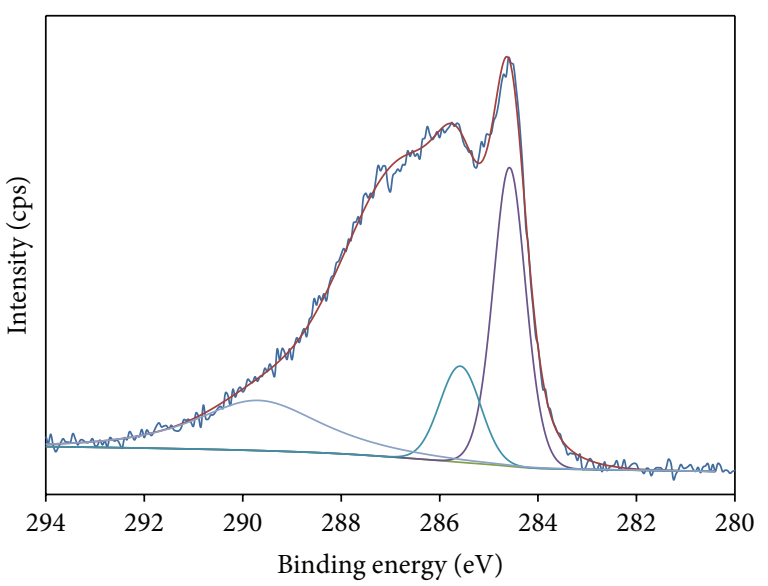

(c)

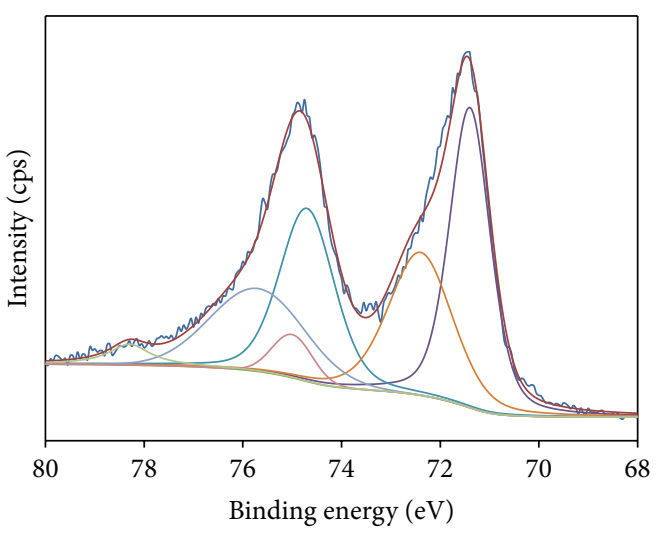

(b)

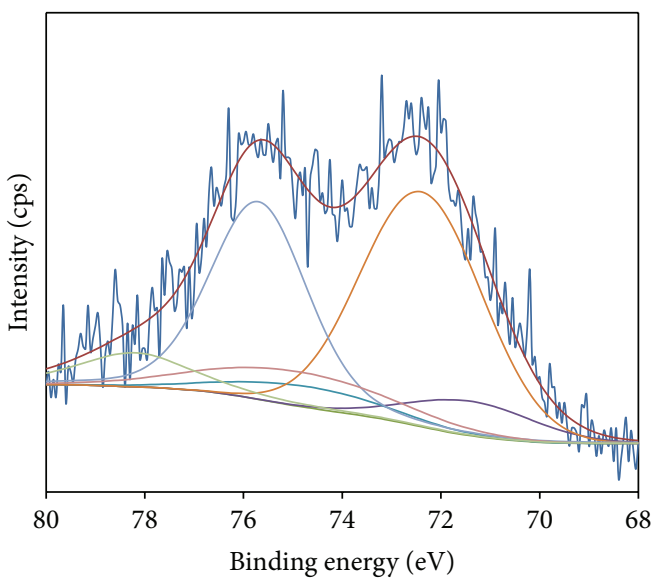

(d)

Figure 4: C 1s (a, c) and Pt 4f (b, d) high-resolution XPS spectra of (a, b) $3.5 \mathrm{wt} \% \mathrm{Pt} / \mathrm{CNTs}$ and (c, d) $3.5 \mathrm{wt} \% \mathrm{Pt} / \mathrm{RGO} @ S i O_{2}$.

the $3.5 \mathrm{wt} \% \mathrm{Pt} / \mathrm{CNTs}$ catalyst. Firstly, there is the effect of the Pt electron structure. In our previous reports [37, 4547], it has been found that the $\mathrm{Pt}^{0}$ species plays a key role in the selectivity to COL in the selective hydrogenation of cinnamaldehyde, and there is a linear correlation between the amount of $\mathrm{Pt}^{0}$ and the selectivity. The more the surface $\mathrm{Pt}^{0}$ content catalyst has, the higher selectivity to COL it exhibits. We have brought out that there is the special effect of carbon support on the amount of $\mathrm{Pt}^{0}$ species [37]. Here, the amount of $\mathrm{Pt}^{0}$ species is $58.6 \%$ and $19.0 \%$ on the surface of $3.5 \mathrm{wt} \% \mathrm{Pt} / \mathrm{CNTs}$ and $3.5 \mathrm{wt} \% \mathrm{Pt} / \mathrm{RGO} @ \mathrm{SiO}_{2}$ (Figure 4, Table 1), respectively, which responds to the selectivity of COL (Table 2). The amount of $\mathrm{Pt}^{0}$ species on the surface of $3.5 \mathrm{wt} \% \mathrm{Pt} / \mathrm{CNTs}$ and $3.5 \mathrm{wt} \% \mathrm{Pt} / \mathrm{RGO} @ \mathrm{SiO}_{2}$ is the important reason for the selectivity of COL. Furthermore, it is noticed that the amount of $\mathrm{Pt}^{0}$ species for $3.5 \mathrm{wt} \% \mathrm{Pt} / \mathrm{CNTs}$ is similar to that of $3.5 \mathrm{wt} \% \mathrm{Pt} /$ graphene (61\%) [37]; however, the selectivity to COL is much lower compared with $3.5 \mathrm{wt} \%$ $\mathrm{Pt} /$ graphene (82\%) [37]. It is obvious that there is not a linear correlation between selectivity to $\mathrm{COL}$ and $\mathrm{Pt}^{0}$ species for $3.5 \mathrm{wt} \% \mathrm{Pt} / \mathrm{CNTs}$, 3.5 wt\% Pt/RGO@SiO 2 , and $3.5 \mathrm{wt} \%$ $\mathrm{Pt} /$ graphene. Thus, we think that the carbon support itself plays other roles besides effect on the formation of $\mathrm{Pt}^{0}$ species in the selective hydrogenation of CAL. The Raman results shown in Table 1 indicate that the value of $I_{\mathrm{D}} / I_{\mathrm{G}}$ is 0.82 and 1.2 for $3.5 \mathrm{wt} \% \mathrm{Pt} / \mathrm{CNTs}$ and $3.5 \mathrm{wt} \% \mathrm{Pt} / \mathrm{RGO} @ \mathrm{SiO}_{2}$, respectively, which is much higher than that of $3.5 \mathrm{wt} \%$ $\mathrm{Pt} /$ graphene (0.29) [37]. It suggests that the graphitization degree of support is listed as follows: graphene > CNTs $>\mathrm{RGO} @ \mathrm{SiO}_{2}$, meaning there are more amounts of the disordered $\mathrm{sp}^{2}$-bonded carbon such as various $-\mathrm{COH}$ and - $\mathrm{COOH}$ groups, on the surface of $3.5 \mathrm{wt} \% \mathrm{Pt} / \mathrm{CNTs}$ and $3.5 \mathrm{wt} \% \mathrm{Pt} / \mathrm{RGO} @ \mathrm{SiO}_{2}$. These groups derived from the low crystallinity degree of the carbon support. Secondly, property of supports can influence the sorption of CAL. According to literatures [9], the worse the crystallinity degree of the carbon support is, the weaker the adsorption of CAL is on its surface. The much lower graphitization degree of support is disadvantage for the weak $\pi-\pi$ interactions between CAL and the surface $\mathrm{sp}^{2}$-bonded carbon support, which results in the low conversion of CAL. Moreover, the weak $\pi-\pi$ interactions can favor the contact of $\mathrm{C}=\mathrm{C}$ with $\mathrm{Pt}$ species due to CAL structure, which leads to the decrease in selectivity to COL and increase in selectivity to HALD. The graphitization degree of $3.5 \mathrm{wt} \% \mathrm{Pt} / \mathrm{CNTs}$ is much higher than that of $3.5 \mathrm{wt} \% \mathrm{Pt} / \mathrm{RGO} @ \mathrm{SiO}_{2}$; thus, the high selectivity to COL may be partly attributed to the better graphitization degree. The 


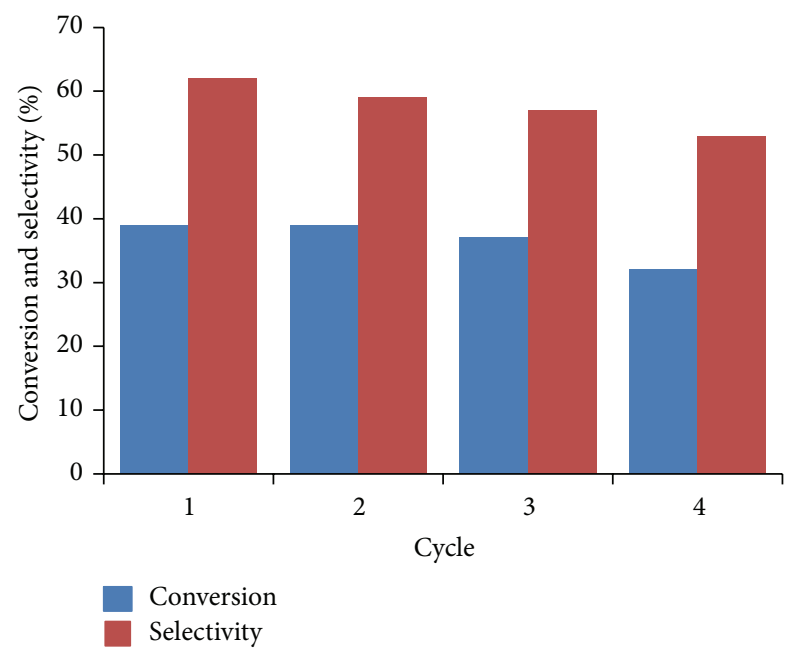

Figure 5: Stability test for $3.5 \mathrm{wt} \% \mathrm{Pt} / \mathrm{CNTs}$ shown as performance versus number of recycling runs. Reaction conditions: $50 \mathrm{mg}$ $3.5 \mathrm{wt} \% \mathrm{Pt} / \mathrm{CNTs}, 1.00 \mathrm{~g} \mathrm{CAL}, 30 \mathrm{~mL}$ isopropanol, $10 \mathrm{bar}_{2}, 60^{\circ} \mathrm{C}$, and $2 \mathrm{~h}$.

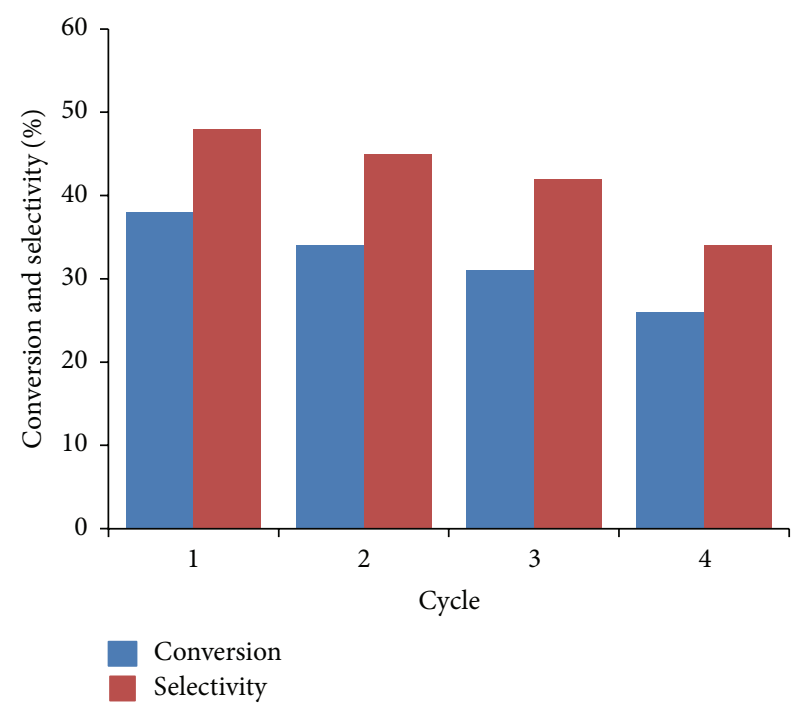

FIGURE 6: Stability test for 3.5 wt\% Pt/RGO@SiO 2 shown as performance versus number of recycling runs. Reaction conditions: $50 \mathrm{mg}$ $3.5 \mathrm{wt} \% \mathrm{Pt} / \mathrm{RGO} @ \mathrm{SiO}_{2}, 1.00 \mathrm{~g} \mathrm{CAL}, 30 \mathrm{~mL}$ isopropanol, $10 \mathrm{bar}_{2}$, $60^{\circ} \mathrm{C}$, and $2 \mathrm{~h}$.

better the graphitized degree carbon support is, the higher the adsorption capacity for CAL it shows on its surface. But the graphitization degree of $3.5 \mathrm{wt} \% \mathrm{Pt} / \mathrm{CNTs}$ is low compared with $3.5 \mathrm{wt} \% \mathrm{Pt} / \mathrm{graphene}$. On the whole, $3.5 \mathrm{wt} \% \mathrm{Pt} / \mathrm{CNT}$ shows low conversion and selectivity which can be ascribed to the weak graphitization degree being not conducive to adsorption of CAL compared with $3.5 \mathrm{wt} \% \mathrm{Pt} /$ graphene, although it also possesses high $\mathrm{Pt}^{0}$ amount. So it can be seen clearly that the graphitization degree of carbon support plays an important role in the selective hydrogenation of CAL.

\section{Conclusion}

In summary, different carbon materials including CNTs and RGO were evaluated as support for Pt nanoparticles. TEM images showed that Pt nanoparticles dispersed well on CNTs and RGO surface with a size of about $4 \mathrm{~nm}$. Compared with $3.5 \mathrm{wt} \% \mathrm{Pt} / \mathrm{RGO} @ \mathrm{SiO}_{2}, 3.5 \mathrm{wt} \% \mathrm{Pt} / \mathrm{CNT}$ shows better selectivity for the hydrogenation of $\mathrm{C}=\mathrm{O}$ bonds. The unique catalytic performance can be attributed to not only the high graphitization degree of CNTs, which facilitate the adsorption of CAL and improve the selectivity of COL, but also the high density of dispersed Pt electron cloud, which benefit for the COL production.

\section{Competing Interests}

The authors declare that there is no conflict of interests regarding the publication of this paper.

\section{Acknowledgments}

This work was supported by Natural Sciences Fund of Heilongjiang Province (B2015009), Postdoctoral ScienceResearch Developmental Foundation of Heilongjiang Province of China (LBH-Q12022), the Scientific Research Foundation for the Returned Overseas Chinese Scholars, State Education Ministry (2013-1792), and Ministry of Human Resources and Social Security (2013-277).

\section{References}

[1] F. Zaera, "Outstanding mechanistic questions in heterogeneous catalysis," The Journal of Physical Chemistry B, vol. 106, no. 16, pp. 4043-4052, 2002.

[2] G. A. Somorjai and J. Y. Park, "Molecular factors of catalytic selectivity," Angewandte Chemie-International Edition, vol. 47, no. 48, pp. 9212-9228, 2008.

[3] P. Gallezot and D. Richard, "Selective hydrogenation of $\alpha, \beta$ unsaturated aldehydes," Catalysis Reviews-Science and Engineering, vol. 40, no. 1-2, pp. 81-126, 1998.

[4] P. Claus, "Selective hydrogenation of $\alpha, \beta$-unsaturated aldehydes and other $\mathrm{C}=\mathrm{O}$ and $\mathrm{C}=\mathrm{C}$ bonds containing compounds," Topics in Catalysis, vol. 5, no. 1, pp. 51-62, 1998.

[5] U. K. Singh and M. A. Vannice, "Kinetics of liquid-phase hydrogenation reactions over supported metal catalysts-a review, Applied Catalysis A: General, vol. 213, no. 1, pp. 1-24, 2001.

[6] J. Teddy, A. Falqui, A. Corrias et al., "Influence of particles alloying on the performances of $\mathrm{Pt}-\mathrm{Ru} / \mathrm{CNT}$ catalysts for selective hydrogenation," Journal of Catalysis, vol. 278, no. 1, pp. 59-70, 2011.

[7] J. P. Stassi, P. D. Zgolicz, S. R. De Miguel, and O. A. Scelza, "Formation of different promoted metallic phases in PtFe and PtSn catalysts supported on carbonaceous materials used for selective hydrogenation," Journal of Catalysis, vol. 306, pp. 1129, 2013.

[8] Y. Yuan, S. Yao, M. Wang, S. Lou, and N. Yan, "Recent progress in chemoselective hydrogenation of $\alpha, \beta$-unsaturated aldehyde to unsaturated alcohol over nanomaterials," Current Organic Chemistry, vol. 17, no. 4, pp. 400-413, 2013. 
[9] P. Mäki-Arvela, J. Hájek, T. Salmi, and D. Y. Murzin, "Chemoselective hydrogenation of carbonyl compounds over heterogeneous catalysts," Applied Catalysis A: General, vol. 292, pp. 1-49, 2005.

[10] Z. Broučková, M. Czaková, and M. Čapka, "Hydrogenation of cinnamaldehyde catalysed by homogeneous and heterogenized rhodium(I) and ruthenium(II) complexes," Journal of Molecular Catalysis, vol. 30, no. 1-2, pp. 241-249, 1985.

[11] C. Stangel, G. Charalambidis, V. Varda, A. G. Coutsolelos, and I. D. Kostas, "Aqueous-organic biphasic hydrogenation of trans-cinnamaldehyde catalyzed by rhodium and ruthenium phosphane-free porphyrin complexes," European Journal of Inorganic Chemistry, no. 30, pp. 4709-4716, 2011.

[12] G. R. Bertolini, C. I. Cabello, M. Muñoz et al., "Catalysts based on $\mathrm{Rh}$ (III)-hexamolybdate $/ \gamma-\mathrm{Al}_{2} \mathrm{O}_{3}$ and their application in the selective hydrogenation of cinnamaldehyde to hydrocinnamaldehyde," Journal of Molecular Catalysis A: Chemical, vol. 366, pp. 109-115, 2013.

[13] T. Mitsudome and K. Kaneda, "Gold nanoparticle catalysts for selective hydrogenations," Green Chemistry, vol. 15, no. 10, pp. 2636-2654, 2013.

[14] H. Vu, F. Gonçalves, R. Philippe et al., "Bimetallic catalysis on carbon nanotubes for the selective hydrogenation of cinnamaldehyde," Journal of Catalysis, vol. 240, no. 1, pp. 18-22, 2006.

[15] Z. Y. Guo, C. X. Xiao, R. V. Maligal-Ganesh et al., "Pt nanoclusters confined within metal-organic framework cavities for chemoselective cinnamaldehyde hydrogenation," ACS Catalysis, vol. 4, no. 5, pp. 1340-1348, 2014.

[16] W. Lin, H. Cheng, L. He, Y. Yu, and F. Zhao, "High performance of Ir-promoted $\mathrm{Ni} / \mathrm{TiO}_{2}$ catalyst toward the selective hydrogenation of cinnamaldehyde," Journal of Catalysis, vol. 303, no. 7, pp. 110-116, 2013.

[17] H. Wang, Y. Shu, M. Zheng, and T. Zhang, "Selective hydrogenation of cinnamaldehyde to hydrocinnamaldehyde over $\mathrm{SiO}_{2}$ supported nickel phosphide catalysts," Catalysis Letters, vol. 124, no. 3-4, pp. 219-225, 2008.

[18] C. Rudolf, B. Dragoi, A. Ungureanu et al., "NiAl and CoAl materials derived from takovite-like LDHs and related structures as efficient chemoselective hydrogenation catalysts," Catalysis Science \& Technology, vol. 4, no. 1, pp. 179-189, 2014.

[19] M. G. Prakash, R. Mahalakshmy, K. R. Krishnamurthy, and B. Viswanathan, "Selective hydrogenation of cinnamaldehyde on nickel nanoparticles supported on titania: role of catalyst preparation methods," Catalysis Science \& Technology, vol. 5, no. 6, pp. 3313-3321, 2015.

[20] M. G. Prakash, R. Mahalakshmy, K. R. Krishnamurthy, and B. Viswanathan, "Studies on $\mathrm{Ni}-\mathrm{M}(\mathrm{M}=\mathrm{Cu}, \mathrm{Ag}, \mathrm{Au})$ bimetallic catalysts for selective hydrogenation of cinnamaldehyde," Catalysis Today, vol. 263, no. 1, pp. 105-111, 2016.

[21] Y. Zhu and F. Zaera, "Selectivity in the catalytic hydrogenation of cinnamaldehyde promoted by $\mathrm{Pt} / \mathrm{SiO}_{2}$ as a function of metal nanoparticle size," Catalysis Science and Technology, vol. 4, no. 4, pp. 955-962, 2014.

[22] N. Mahata, F. Gonçalves, M. F. R. Pereira, and J. L. Figueiredo, "Selective hydrogenation of cinnamaldehyde to cinnamyl alcohol over mesoporous carbon supported $\mathrm{Fe}$ and $\mathrm{Zn}$ promoted $\mathrm{Pt}$ catalyst," Applied Catalysis A: General, vol. 339, no. 2, pp. 159168, 2008.

[23] N. Job, R. Pirard, J. Marien, and J.-P. Pirard, "Porous carbon xerogels with texture tailored by $\mathrm{pH}$ control during sol-gel process," Carbon, vol. 42, no. 3, pp. 619-628, 2004.
[24] M. S. Ide, B. Hao, M. Neurock, and R. J. Davis, "Mechanistic insights on the hydrogenation of $\alpha, \beta$-unsaturated ketones and aldehydes to unsaturated alcohols over metal catalysts," ACS Catalysis, vol. 2, no. 4, pp. 671-683, 2012.

[25] J. H. Vleeming, B. F. M. Kuster, and G. B. Marin, "Effect of platinum particle size and catalyst support on the platinum catalyzed selective oxidation of carbohydrates," Catalysis Letters, vol. 46, no. 1-2, pp. 187-194, 1997.

[26] S. Bhogeswararao and D. Srinivas, "Intramolecular selective hydrogenation of cinnamaldehyde over $\mathrm{CeO}_{2}-\mathrm{ZrO}_{2}$-supported Pt catalysts," Journal of Catalysis, vol. 285, no. 1, pp. 31-40, 2012.

[27] H. G. Manyar, B. Yang, H. Daly et al., "Selective hydrogenation of $\alpha, \beta$-unsaturated aldehydes and ketones using novel manganese oxide and platinum supported on manganese oxide octahedral molecular sieves as catalysts," ChemCatChem, vol. 5, no. 2, pp. 506-512, 2013.

[28] K. Liberková and R. Touroude, "Performance of $\mathrm{Pt} / \mathrm{SnO}_{2}$ catalyst in the gas phase hydrogenation of crotonaldehyde," Journal of Molecular Catalysis A: Chemical, vol. 180, no. 1-2, pp. 221-230, 2002.

[29] A. Huidobro, A. Sepúlveda-Escribano, and F. RodríguezReinoso, "Vapor-phase hydrogenation of crotonaldehyde on titania-supported Pt and PtSn SMSI catalysts," Journal of Catalysis, vol. 212, no. 1, pp. 94-103, 2002.

[30] X. Yang, L. Wu, L. Ma, X. Li, T. Wang, and S. Liao, "Pd nano-particles (NPs) confined in titanate nanotubes (TNTs) for hydrogenation of cinnamaldehyde," Catalysis Communications, vol. 59, pp. 184-188, 2015.

[31] E. V. Ramos-Fernández, A. F. P. Ferreira, A. SepúlvedaEscribano, F. Kapteijn, and F. Rodríguez-Reinoso, "Enhancing the catalytic performance of $\mathrm{Pt} / \mathrm{ZnO}$ in the selective hydrogenation of cinnamaldehyde by $\mathrm{Cr}$ addition to the support," Journal of Catalysis, vol. 258, no. 1, pp. 52-60, 2008.

[32] Z. Sun, Z. Rong, Y. Wang, Y. Xia, W. Du, and Y. Wang, "Selective hydrogenation of cinnamaldehyde over Pt nanoparticles deposited on reduced graphene oxide," RSC Advances, vol. 4, no. 4, pp. 1874-1878, 2014.

[33] J. Shi, R. Nie, P. Chen, and Z. Hou, "Selective hydrogenation of cinnamaldehyde over reduced graphene oxide supported $\mathrm{Pt}$ catalyst," Catalysis Communications, vol. 41, pp. 101-105, 2013.

[34] Y. Wang, Z. Rong, Y. Wang, P. Zhang, Y. Wang, and J. $\mathrm{Qu}$, "Ruthenium nanoparticles loaded on multiwalled carbon nanotubes for liquid-phase hydrogenation of fine chemicals: an exploration of confinement effect," Journal of Catalysis, vol. 329, no. 28, pp. 95-106, 2015.

[35] C. Vriamont, T. Haynes, E. McCague-Murphy, F. Pennetreau, O. Riant, and S. Hermans, "Covalently and non-covalently immobilized clusters onto nanocarbons as catalysts precursors for cinnamaldehyde selective hydrogenation," Journal of Catalysis, vol. 329, Article ID 11784, pp. 389-400, 2015.

[36] L. J. Malobela, J. Heveling, W. G. Augustyn, and L. M. Cele, "Nickel-cobalt on carbonaceous supports for the selective catalytic hydrogenation of cinnamaldehyde," Industrial and Engineering Chemistry Research, vol. 53, no. 36, pp. 13910-13919, 2014.

[37] X. Ji, X. Niu, B. Li et al., "Selective hydrogenation of cinnamaldehyde to cinnamal alcohol over platinum/graphene catalysts," ChemCatChem, vol. 6, no. 11, pp. 3246-3253, 2014.

[38] J. Yang, C. G. Tian, L. Wang, and H. G. Fu, "An effective strategy for small-sized and highly-dispersed palladium nanoparticles supported on graphene with excellent performance for formic 
acid oxidation," Journal of Materials Chemistry, vol. 21, no. 10, pp. 3384-3390, 2011.

[39] Z.-T. Liu, C.-X. Wang, Z.-W. Liu, and J. Lu, "Selective hydrogenation of cinnamaldehyde over Pt-supported multi-walled carbon nanotubes: insights into the tube-size effects," Applied Catalysis A: General, vol. 344, no. 1-2, pp. 114-123, 2008.

[40] F. Tuinstra and J. L. Koenig, "Raman spectrum of graphite," The Journal of Chemical Physics, vol. 53, no. 3, pp. 1126-1130, 1970.

[41] K. Bustos-Ramirez, C. E. Barrera-Diaz, M. De Icaza, A. L. Martínez-Hernández, and C. Velasco-Santos, "Photocatalytic activity in phenol removal of water from graphite and graphene oxides: effect of degassing and chemical oxidation in the synthesis process," Journal of Chemistry, vol. 2015, Article ID 254631, 10 pages, 2015.

[42] X. M. Feng, R. M. Li, C. H. Hu, and W. H. Hou, "Direct electron transfer and electrocatalysis of hemoglobin immobilized on graphene-Pt nanocomposite," Journal of Electroanalytical Chemistry, vol. 657, no. 1-2, pp. 28-33, 2011.

[43] S. Sharma, A. Ganguly, P. Papakonstantinou et al., "Rapid microwave synthesis of $\mathrm{CO}$ tolerant Reduced graphene oxidesupported platinum electrocatalysts for oxidation of methanol," Journal of Physical Chemistry C, vol. 114, no. 45, pp. 1945919466, 2010.

[44] X. Yu and S. Ye, "Recent advances in activity and durability enhancement of $\mathrm{Pt} / \mathrm{C}$ catalytic cathode in PEMFC. Part II: degradation mechanism and durability enhancement of carbon supported platinum catalyst," Journal of Power Sources, vol. 172, no. 1, pp. 145-154, 2007.

[45] D. Wang, Y. Zhu, C. Tian et al., "Synergistic effect of $\mathrm{Mo}_{2} \mathrm{~N}$ and $\mathrm{Pt}$ for promoted selective hydrogenation of cinnamaldehyde over Pt- $\mathrm{Mo}_{2} \mathrm{~N} / \mathrm{SBA}-15$," Catalysis Science \& Technology, vol. 6, no. 7, pp. 2403-2412, 2016.

[46] D. Wang, Y. J. Zhu, C. G. Tian et al., "Synergistic effect of tungsten nitride and palladium for the selective hydrogenation of cinnamaldehyde at the $\mathrm{C}=\mathrm{C}$ bond," ChemCatChem, vol. 8 , no. 9, pp. 1718-1726, 2016.

[47] Q. Zheng, D. Wang, F. L. Yuan et al., "An effective Co-promoted platinum of Co-Pt/SBA-15 catalyst for selective hydrogenation of cinnamaldehyde to cinnamyl alcohol," Catalysis Letters, vol. 146, no. 8, pp. 1535-1543, 2016. 

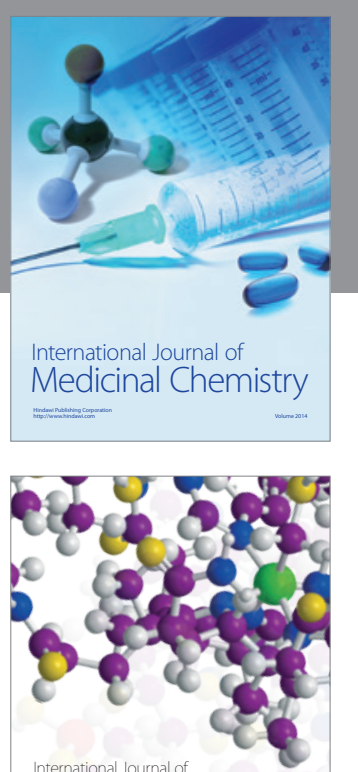

Carbohydrate Chemistry

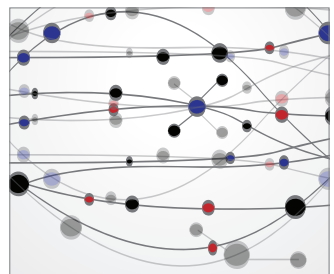

The Scientific World Journal
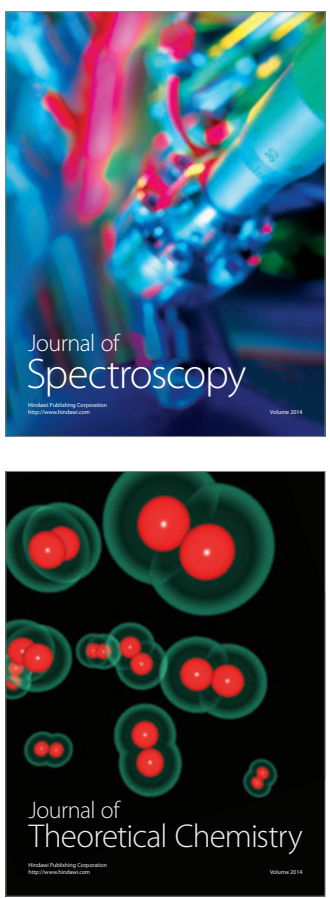
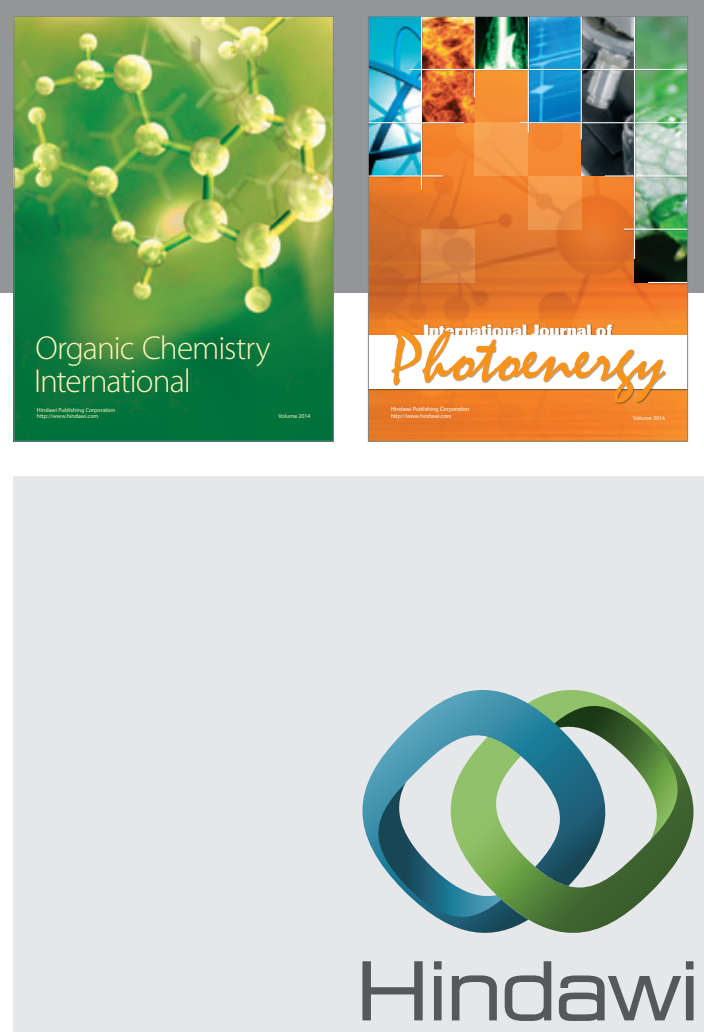

Submit your manuscripts at

http://www.hindawi.com

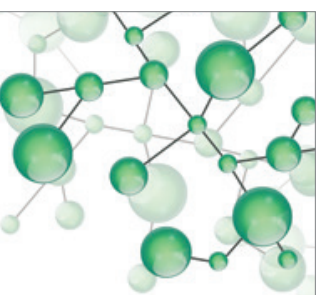

International Journal of

Inorganic Chemistry

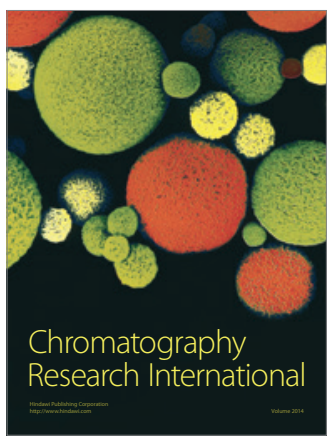

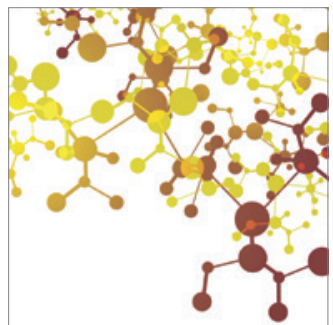

Applied Chemistry
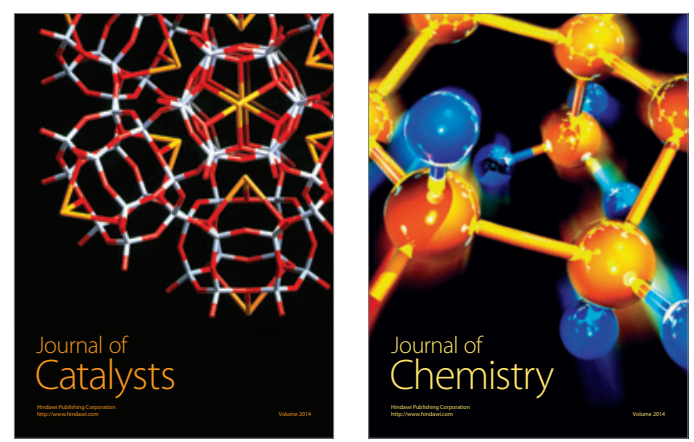
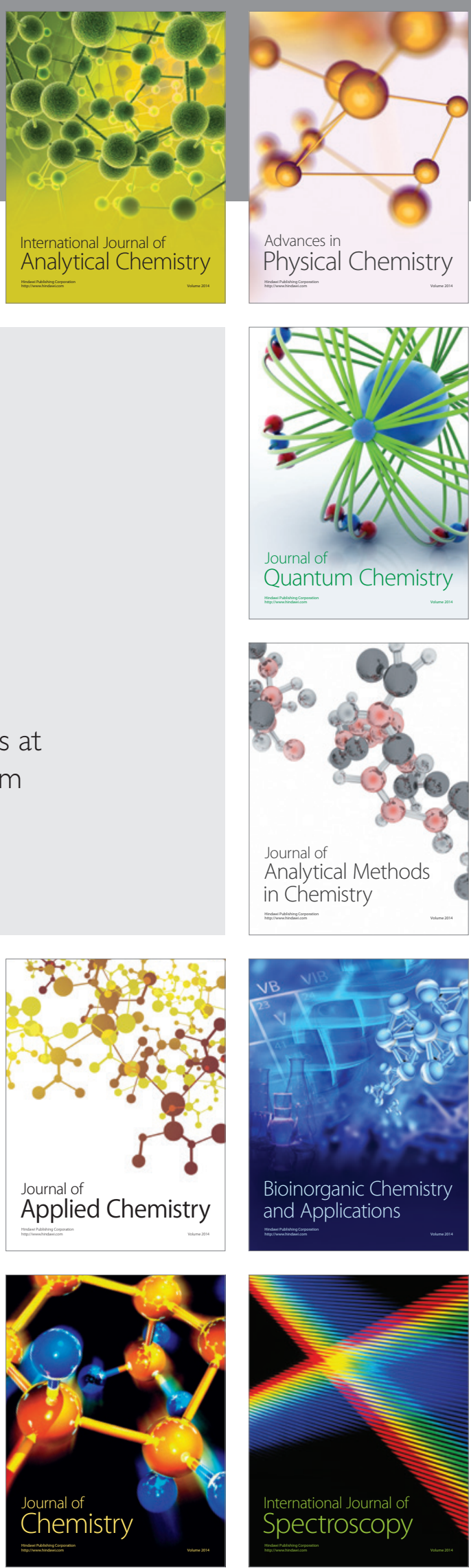